\title{
VIAGENS DE ABEL: A BUSCA \\ DA CIDADE EM AVALOVARA, \\ DE OSMAN LINS ${ }^{*}$
}

Regina Dalcastagnè Universidade de Brasília

De uma cidade, não aproveitamos as suas sete ou setenta e sete maravilhas, mas a resposta que dá às nossas perguntas.

Italo Calvino

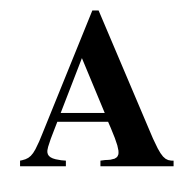

travessar oceanos, enfrentar exércitos, descer aos infernos - não existem fronteiras para aquele que busca, seja o objeto dessa busca um reino improvável, a mulher amada ou uma baleia branca. Desde que o primeiro homem se retirou do convívio com os seus no encalço de algo que apenas podia intuir, uma multidão o sucedeu - herdeiros de uma angústia que os sufoca e os impulsiona. Abel, protagonista do romance Avalovara, de Osman Lins (publicado em 1973), compartilha esse mesmo destino, escravo e senhor de uma razão que o precede e que veio depois dele. Saindo em busca da Cidade, que se faz anunciada dez anos antes no fundo de uma cisterna, ele empreende uma grande viagem, onde terá que se confrontar com territórios vazios, monstros sinistros e desilusões ainda mais terríveis.

Abel, embora personagem de um outro, é ainda aquele que habita um mundo povoado por homens, e, com eles, usufrui de uma

\footnotetext{
" Este artigo é a versão modificada de um capítulo de minha tese de doutorado, Uma obra em movimento: leitura(s) de Avalovara, de Osman Lins, defendida na Unicamp.
} 
história comum, feita de enfrentamentos e paixões, alegrias e dor. Idênticas experiências que, num canto ou noutro do globo, podem ser vividas de maneiras completamente diferentes. Isso porque, ao ocupar a Terra, os homens semeiam culturas. Abel é humano, mas é também ocidental; nasce impregnado pela tradição judaico-cristã. Mitos e deuses alheios a essa tradição podem até auxiliar na trajetória do protagonista, como é o caso do Avalovara, ${ }^{1}$ mas não a sustentam. Abel está intrinsecamente ligado à cosmogonia bíblica. Ele é descendente de Adão e Eva, irmão de Caim.

Abel, no Gênesis, é o preferido de seu deus, o que desperta no irmão o ódio e o leva ao fraticídio. Mas é também o fraco, aquele que não vingou, o que pereceu. Seu nome significa vento passageiro, ninharia. ${ }^{2}$ Caim, o assassino, o revelador da morte, foi "o primeiro homem a retirar-se da presença de Jeová e partir, numa infinda caminhada, em direção ao sol levante". ${ }^{3}$ Carregava consigo a marca de Deus, "a fim de que não fosse morto por quem o encontrasse". ${ }^{4}$ Foi Caim que construiu a cidade, ele quem povoou o mundo:

Partiremos para o deserto dos homens, e que os homens, inumeravelmente, povoarão. Nós nos guiaremos pela aurora sempre renovada... E será por não nos determos em parte alguma que estaremos sempre em toda parte. Nossa vida errante nos permitirá medir a terra e, ao mesmo tempo, nós a edificaremos. ${ }^{5}$

$\mathrm{Na}$ face de cada homem que veio depois se exibe ainda a sua marca, sinal que distingue e une. O Abel que circula pelas páginas

${ }^{1} \mathrm{O}$ nome do pássaro, e do livro, é uma redução da palavra Avalokitesvara um deus oriental que representa a misericórdia e a compaixão. (COTTERELL, 1988, p. 80-81).

${ }^{2}$ BÍBLIA, 1982, p. 32.

${ }^{3}$ CHEVALIER e GHEERBRANT, 1991, p. 162.

${ }^{4}$ BÍBLIA, 1982, p. 32 ( Gn, 4,15).

${ }^{5}$ Luc Estang, Le jour de Caïm, cit. in CHEVALIER e GHEERBRANT, 1991, p. 163. 
de Avalovara é o mesmo que teve a garganta rasgada na Bíblia, mas já é inteiramente outro. Se observado por esse ângulo, veríamos que sua fronte guarda uma pequena mancha, ao mesmo tempo em que uma tênue cicatriz se insinua em seu pescoço. É um Abel renascido, ainda aquele, mas já carregando a experiência dos que se seguiram, herdeiros de seu irmão, criadores e habitantes de cidades. Vértice de um triângulo que une os três primeiros homens, ele não é nem aquele que habitou o Paraíso - "nascemos expulsos e caídos" o que edificou as cidades. Abel não passa de um "vento passageiro", e esse é seu tormento primordial.

Aos 16 anos de idade, jogando tarrafa numa cisterna, procurando não peixes, mas respostas às suas indagações, Abel se confronta com a morte e sai ileso. Ao mesmo tempo em que é irresistivelmente atraído para o fundo das águas, lá, onde a morte o espera, algo impede que ele se atire. Rompido o encanto, ele se sente como se "houvesse mergulhado, lidado com o Não, escapado". 7 Tal como José, Abel é libertado do poço, de onde sai, como sobrevivente, para retraçar seu destino. Esquivando-se da morte, ele não se faz provedor do Egito, mas jovem errante pelos chãos europeus. Na ânsia de perdurar, deseja talvez o lugar do irmão. Mas não é Caim, não pode erguer cidades que há tantos séculos já estão lá, enraizadas em sangue e história, tragédias e cultura.

Por isso ele sai ao encalço da Cidade, visão abstrata e carregada de fascínio que lhe escapa à compreensão e o persegue com seus sortilégios. Abel a busca já cheio de ressalvas, parece que se justificando sempre pela decepção que virá - jamais será a sua cidade. Não sabe porque a quer. Talvez imagine que com ela possa se livrar definitivamente do monstro peçonhento que o abordava na infância; ${ }^{8}$

${ }^{6}$ LINS, 1973, p. 236.

7 LINS, 1973, p. 78.

8 "Sinto o cheiro do animal que desde a infância, sempre que interrogo coisas simples e indizíveis como a superfície de um espelho e as paredes lisas, aparece atrás de mim exalando a sua inhaca que significa: 'Não consegues, Abel'” (LINS, 1973, p. 52). 
talvez precise descrevê-la, escrevê-la, para fazê-la sua, conquistá-la ao irmão. Mas antes têm de encontrá-la, e ela nunca está lá. A primeira parte de seu percurso se dá na Europa, entre fabulosas catedrais e palácios luxuosos - arte e arquitetura. São milhares de quilômetros transitados, num itinerário que tem, ele próprio reconhece, "alguma coisa de demência".

Em cada cidade visitada, Abel encontra apenas um pálido reflexo daquela que busca: "Farejo, cão, nas cidades percorridas, uma presa intangível, uma caça que vi, eu, cão, por um espelho, mas da qual não cheguei a distinguir o cheiro". ${ }^{10}$ Mas não se sente fraudado, não crê desperdiçados seus dias; nelas estariam as instruções sobre "o livro que em segredo aspiro escrever e cujo tema central seria o modo como as coisas, havendo transposto um limiar, ascendem, mediante novas relações, ao nível da ficção". ${ }^{11}$ A Cidade que ele procura está desde sempre ligada a um texto futuro, a um livro que pretende se fazer possível. A dificuldade da busca se alia ao fato de que a Cidade se transforma, muda suas feições permanentemente, como, aliás, toda cidade, todo texto vivo, incluindo aí o próprio Avalovara.

Anneliese Roos, uma alemã que recita versos de Anacreonte para Abel em Paris (os mesmos versos que Abel lia, isolado, na cisterna), é representação dessa inconstância. Ela é "o círculo, a volta, o progresso ilusório". ${ }^{12}$ Em seu corpo, flutuam cidades, incalculáveis e desertas. Símbolo do inatingível, corporificação do urbano, Roos é ainda a mulher por quem Abel se apaixona, além de declarada personagem de um autor que se insinua vez ou outra. Essa ambigüidade entre o ser e o representar é fundamental em Avalovara. Cada uma das personagens do romance é e representa ao mesmo tempo; só assim podem dar conta da própria comple-

\footnotetext{
9 LINS, 1973, p. 178.

${ }^{10}$ LINS, 1973, p. 179.

${ }^{11}$ LINS, 1973, p. 179.

${ }^{12}$ LINS, 1973, p. 25.
} 
xidade estrutural. Anneliese simboliza as cidades que transporta no corpo, mas também é essas cidades.

Tudo no romance possui essa ambivalência. Nada é apenas o que parece ser em determinado momento, sob determinado ângulo. Imagens e sentimentos, as próprias personagens - assim como a Cidade - se vão transformando, desconstruindo-se e refazendo-se ao longo do livro. Abel quer Anneliese tanto quanto deseja a Cidade e a ambas, de alguma maneira, teme. Observando, atento, um pássaro que se aproxima de Roos num parque, ele atrela seu destino junto a ela com o da ave: "suba o pássaro à mão dessa estrangeira e estou para sempre enredado num baraço". ${ }^{13}$

Mesmo desejando-a, Abel bate palmas e espanta a ave, confirmando assim a separação que virá em breve: "Com o meu gesto, desapareci - como o pássaro - dos olhos de Roos". ${ }^{14}$ A Cidade não o assusta menos. Suas metamorfoses, suas múltiplas faces, os acréscimos e perdas que, ele sabe, a constituem, tudo o submerge em dúvidas. Como a reconhecerá? "Vendo-a, encontrarei", ${ }^{15}$ responde. Mas se Roos abriga, dentre todas as cidades, aquela que ele procura ${ }^{16}$ por que o reflexo instintivo de afastamento? Talvez porque o encontro implique no fim da busca; talvez porque o medo da decepção seja maior; quem sabe porque ele ainda não se julgue preparado para a resposta que aguarda desde menino - resposta para uma pergunta que já não reconhece.

A Cidade é e está em Anneliese, mas Abel não a alcança porque ela é apenas parte do percurso, trecho da viagem que, sob novas feições, prosseguirá com Cecília e , suas duas outras paixões, vividas em tempos subseqüentes. Encontrar a Cidade "cuja imagem aparece uma tarde, miniatural, vinda através de mares e estações,

\footnotetext{
${ }^{13}$ LINS, 1973, p. 56.

${ }^{14}$ LINS, 1973, p. 56.

${ }^{15}$ LINS, 1973, p. 91.

${ }^{16}$ LINS, 1973, p. 93.
} 
como o espectro de um pássaro ou de um antepassado", ${ }^{17}$ pode parecer, em certos momentos, menos importante do que buscá-la. Mas não é tão simples. Basta andar um pouco mais, dar alguns passos em outra direção para que o sentido da busca e do encontro em Avalovara se transforme de novo, invertendo-se, revigorandose incessantemente. Aqui, é possível lembrar o edifício gótico, tal como descrito por Hauser - uma massa que obriga o "espectador a mudar constantemente de ponto de vista, e somente lhe permite obter uma visão de conjunto através de seu próprio movimento, ação e poder de reconstituição". ${ }^{18}$

Invejado destino de Caim, texto futuro, resposta a indagações desconhecidas - a Cidade que Abel procura é também protótipo divino, a Jerusalém celestial que, no romance como no Apocalipse, desce dos céus "pronta como uma esposa que se enfeitou para seu marido". ${ }^{19}$ Essa Jerusalém, criada por Deus muito antes da primeira cidade ter sido erguida pelas mãos do homem, teria sido mostrada a Adão antes do pecado. "Espectro de um antepassado", a Cidade que se insinua na existência de Abel pode ser aquela mesma que foi apresentada um dia a seu ancestral. Remota memória, nostálgica lembrança do Paraíso, sua imagem se confunde com a idéia de Criação.

Caso se entenda, como Mircea Eliade, que "toda criação repete o ato cosmogônico pré-eminente, a criação do mundo", ${ }^{21}$ pode-se perceber porque a Cidade de Abel está ligada a um livro. Através dela ele chegará ao texto, à obra que, por sua vez, o levará de volta ao momento da Criação. Esse encontro inclui, necessariamente, a busca - trajeto de ida e volta que Abel crava em sua própria carne, conduzindo e conduzido pelas três mulheres que ama. Se a Cidade é representação da nostalgia do Paraíso, o percurso que leva até ela

\footnotetext{
${ }^{17}$ LINS, 1973, p. 90-91.

${ }^{18}$ HAUSER, 1982, vol. 1, p. 326.

19 BÍBLIA, 1982, p. 1469 (Ap, 21,2).

${ }^{20}$ ELIADE, 1992, p. 20.

${ }^{21}$ ELIADE, 1992, p. 27.
} 
é o mesmo que transportará Abel e ao Jardim original. Esse percurso vai em direção ao centro, ao $\mathrm{N}$ do palíndromo mágico. ${ }^{22}$ É lá, no centro, que se encontra o Paraíso - umbigo do mundo. ${ }^{23}$

Seu acesso é difícil,

a estrada é árdua, repleta de perigos, porque, na verdade, representa um ritual de passagem do âmbito profano para o sagrado, do efêmero e ilusório para a realidade e a eternidade, da morte para a vida, do homem para a divindade. Chegar ao centro equivale a uma consagração, uma iniciação; a existência profana e ilusória de ontem dá lugar a uma nova, a uma vida que é real, duradoura, eficiente. ${ }^{24}$

Esse caráter iniciático da busca de Abel possui múltiplas perspectivas. Abel é um homem, mas é também uma personagem e um autor. "Transcender", para ele, é muito mais que um movimento em direção ao místico - é toda uma escalada em torno do sentido de criação.

Por isso mesmo, mais do que qualquer mistério divino, o que Abel persegue são construções humanas (ainda que boa parte delas seja dedicada aos deuses). A grande Criação é apenas exemplar, insuficiente aos homens para se sentirem integrados ao cosmos, ou aos seus. Erguer cidades, arrancar figuras de dentro de um bloco de pedra, construir uma vida manuseando somente palavras, todo ato criativo pode ser considerado uma afronta aos deuses. O poder da criação talvez já não lhes seja exclusivo, quem sabe nem lhes pertença mais. Pode ter sido roubado junto àquela maçã, ou com o fogo transportado por Prometeu. A punição sem dúvida foi severa, mas o legado da liberdade é um bem excessivamente precioso para que o homem venha algum dia a se arrepender.

${ }^{22}$ Avalovara é construído a partir da intersecção entre uma espiral e um quadrado "mágico" formado pelo palíndromo SATOR AREPO TENET OPERA ROTAS. São oito linhas narrativas diferentes, uma para cada letra do palíndromo, que se alternam conforme a espiral passa pelas casas do quadrado. ${ }^{23}$ Ver ELIADE, 1992, p. 23-26.

${ }^{24}$ ELIADE, 1992, p. 27. 
Abel, ao sair atrás do destino de Caim, reclama, de certa forma, seu quinhão nessa herança. Abdica do privilégio de ser o preferido, rejeita o sacrifício, e escolhe o incerto, aquilo que apenas se anuncia, promessas sussurradas ao vento. Ele renuncia a Deus em benefício de um autor, que o convida a exercer sua liberdade, a ser aquele que busca, o que cria. Quem é o traidor e quem é o traído aqui? Abel engana a entidade divina e é enganado pelo mortal. Afinal, o que é um autor senão outro criador? No entanto, é humano. E essa parece ser a escolha definitiva de Abel. Ele opta pelos homens, Prometeu moderno, e passa a ser tentado e castigado pelos deuses.

O conflito, que lhe é inerente, será seu eterno companheiro. Estaria com ele no alto do Cáucaso, observando seu fígado ser diariamente devorado pela águia. Está ao seu lado no guichê da Caixa Econômica Federal, enquanto o artista vai sendo mastigado pelo burocrata. Abel escolheu o destino dos homens, mas estes se realizam imitando os deuses. Gerando obras que pretendem pertencer à eternidade, eles tentam impô-las diante da Criação. Chegam a crer que aquilo que surge de suas mãos pode ser ainda mais belo do que o resultado do trabalho divino. Witelo, amigo de Tomás de Aquino, acreditava que "o artificial parece mais belo que o natural. Em outras palavras, que o artista humano poderia concentrar em sua produção uma idéia mais significativa e um arranjo mais harmonioso do que qualquer outro proporcionado pela natureza". ${ }^{25}$

Em meio à discussão, Abel se questiona sobre o que produzir - um livro que fale dos homens aos homens, de um cotidiano

${ }^{25}$ STITES, 1940, p. 423. Também Hildeberto de Lavardin, poeta do início do século XII, dizia a respeito da beleza grandiosa e melancólica das ruínas de Roma: "As estátuas de tuas divindades são mais belas do que os próprios deuses; estes as admiram e gostariam de se assemelhar a elas. A natureza não podia criar deuses de tão formoso semblante: só a imaginação do homem poderia construir imagens tão admiráveis. Reverenciem-nas: se as honra mais pelo prestígio da arte do que por sua pretendida divindade" (cit. in BRUYNE, 1958, p. 114). 
histórico ${ }^{26}$ que jamais será substituído, já que único, ou uma obra que instaure um novo diálogo com os deuses, que se inscreva na grande jornada humana em busca do perene, daquilo que pode se igualar ou mesmo superar a criação divina. Ao sair à caça da Cidade, Abel também está cercando a possibilidade de solução desse conflito. Está atrás de uma resposta que só se dará através de novos e sucessivos embates. As dúvidas de Abel, acerca do mundo que habita e dos homens com quem ele compartilha esse mundo e essas incertezas, serão respondidas com outras indagações, sempre mais complexas, quase intraduzíveis. Há uma esfinge no meio do caminho e para onde quer que ele se volte sua sombra o perseguirá.

Nessa primeira parte do percurso, nesse deslocar-se alucinado pela Europa, Abel indaga cidades. Amsterdam, Lausanne, Reims, Milão, Verona, Pádua, Amboise, Veneza, Paris, Ravena, Ferrara, Antuérpia, Florença, Pisa, Roma, Nápoles, Assis, Arezzo, Londres... Se "a arte de 'moldar' frases tem como equivalente uma arte de moldar percursos", como quer Certeau, ${ }^{27}$ é ali que Abel começa a construir o seu texto. Esboça-o na linha invisível que liga uma cidade a outra, rabisca nos muros, nas paredes dos palácios, nos rios e trens que o transportam. Tênue, sua escrita se vai efetuando, um sentido qualquer se insinua, entrevê-se a conexão entre um espaço conquistado e aquele outro, inalcançável; entre o texto possível e o sonhado.

Ao indagar cidades Abel também é indagado. Em meio ao percurso, deixa-se invadir por elas, é percorrido e abandonado. Descrevendo-as pretende recuperá-las, aprisioná-las num texto para então desvendá-las, possuí-las. Mas nem como personagens elas se submetem; há lacunas, intervalos e silêncios em suas praças, em seus monumentos. As cidades no corpo de Anneliese Roos são vazias de gente. Embora edificadas por homens, elas perdem a dimensão humana quando estes estão ausentes - passam a compôr um

${ }^{26}$ Que vem a ser, precisamente, a ditadura militar brasileira nos anos 70 .

${ }^{27}$ CERTEAU, 1994, p. 179. 
cenário, grandioso, belo, mas saqueado. Marco Polo descreveu o esplendor e o mistério das vilas e cidades orientais, mas em momento algum esqueceu dos homens visitados. Eles estão ali; há sete séculos vivem em seus escritos e habitam suas cidades. Continuam realizando suas oferendas, dançando em suas grandes festas, negociando seus produtos. Há sete séculos mantêm o brilho e o encanto de suas casas e palácios.

As narrativas de viagens foram se transformando ao longo de todo esse tempo, como se transformaram os itinerários e os próprios viajantes. De Marco Polo, de quem se dizia que "não houve cristão, nem sarraceno, nem pagão, nem tártaro, nem homem algum de geração alguma, que tanto tivesse visto e sabido das maravilhas e diversidades do mundo", ${ }^{28}$ a Claude Lévi-Strauss que inicia seu Tristes tropiques dizendo odiar as viagens e os exploradores, ${ }^{29}$ todo um universo de expectativas e ilusões foi deslocado, recambiado, transferido. Desapareceram os monstros legendários, as grandes maravilhas, o absolutamente outro. Foram sendo substituídos, aos poucos, pelas descrições naturalistas, pela ciência, pela coleta dos mitos, pelo próprio etnólogo.

Abel é resultado desse processo. Um homem do Novo Mundo que faz o caminho de volta. Não é o índio, o bom selvagem, mas certamente ainda é o outro. Branco e de olhos azuis, herança da invasão holandesa no nordeste brasileiro, ele atravessa os mesmos mares, tantas vezes antes navegados, para chegar a um território povoado de maravilhas; não as naturais, engendradas pelos deuses, mas aquelas que nasceram das mãos dos homens. A Cidade buscada por Abel seria, então, o equivalente humano do paraíso terrestre

${ }^{28}$ POLO, 1994, p. 34. Embora publicado em geral sob o nome do mercador veneziano, o relato de suas viagens foi ditado por ele e redigido por um companheiro de prisão. Está na terceira pessoa.

29 "Je hais les voyages et les explorateurs. Et voici que je m'apprête à raconter mes expéditions" (LÉVI-STRAUSS, 1988, p. 9). 
perseguido pelos viajantes medievais. ${ }^{30} \mathrm{E}$ as descrições que ele faz das cidades expressariam o mesmo êxtase que os grandes navegantes sentiam, e relatavam, ao descobrir rios e pomares que thes indicavam talvez a proximidade, talvez um reflexo do Jardim ${ }^{31}$ - indícios.

Descendente de Marco Polo e Mandeville, de Colombo, Fernão de Magalhães e Vasco da Gama, Abel transporta em si a nostalgia do paraíso, irreprimível e ancestral desejo de atingir o inalcançável. Cúmplice dos antigos, Abel não pode deixar de ser também solidário com os modernos, com a sua desilusão diante dos vestígios de uma realidade que, eles sabem, não existe mais. "A viagem agora, mais do que nunca, coloca o viajante diante de um espelho: onde ele pensa encontrar o outro, vê a si mesmo". ${ }^{32}$ Deslocando-se de maneira meio alucinada pela Europa, Abel reconhece seu próprio reflexo, mas vira o rosto e prossegue, "vou e vou". ${ }^{33}$ Insiste em buscar a Cidade, que se revelará, bem mais tarde, pútrida e contaminada.

Mesmo sem querer, ou apenas sem saber, Abel constrói um percurso que o levará de volta à cisterna, de volta a si mesmo. A Europa, de promessa de encontro, desfaz-se em novos pontos de partida, prenúncio de outras descobertas. Viajando em busca de um texto futuro, Abel é transportado a escritos passados, linhas borradas pelo tempo, que, no entanto, o carregam de volta para casa. Mais ou menos como Marco Polo, magistralmente atualizado por Italo Calvino, explicava a Kublai Khan:

30 "O tema do paraíso é um dos mais importantes da literatura de viagem na Idade Média. O paraíso é objeto de uma busca muito real e, se às vezes alguns viajantes afirmam que nunca chegarão lá, outros continuam a acreditar nele" (KAPPLER, 1994, p. 116).

31 ..."e se por ventura esse rio não sair do paraíso, isso parecerá ainda mais maravilhoso, pois não acredito que se tenha visto em todo o mundo outro rio tão grande e tão profundo" (Colombo, cit. in KAPPLER, 1994, p. 126).

32 MASSI, 1992, p. 193.

33 LINS, 1973, p. 178. 
quanto mais (ele) se perdia em bairros desconhecidos de cidades distantes, melhor compreendia as outras cidades que havia atravessado para chegar até lá, e reconstituía as etapas de suas viagens, e aprendia a conhecer o porto de onde havia zarpado, e os lugares familiares de sua juventude, e os arredores de casa, e uma pracinha de Veneza em que corria quando era criança. ${ }^{34}$

Mas nem por isso Abel ou Marco Polo viajam com os olhos voltados para trás. Seus itinerários se estabelecem através de escolhas, opções feitas ao longo da vida, no contínuo materializar-se das coisas. Passado e futuro se transformam ao longo da viagem, dando lugar a um presente que é sempre imprevisto:

aquilo que ele procurava estava diante de si, e, mesmo que se tratasse do passado, era um passado que mudava à medida que ele prosseguia a sua viagem, porque o passado do viajante muda de acordo com o itinerário realizado, não o passado recente ao qual cada dia que passa acrescenta um dia, mas um passado mais remoto. Ao chegar a uma nova cidade, o viajante reencontra um passado que não lembrava existir: a surpresa daquilo que você deixou de ser ou deixou de possuir revelase nos lugares estranhos, não nos conhecidos. ${ }^{35}$

Esse poder de reconstrução do passado, que o Marco Polo de Calvino atribui à viagem, é inerente à narrativa. Dar ordem aos acontecimentos, emprestar-lhes sentido, é redimensionar a existência, dialogar com o passado. Talvez por isso Abel busque, concomitantemente à Cidade, um texto: "onde está impresso ou se me cabe escrevê-lo, não sei". ${ }^{36}$ Percorrendo as ruas, bibliotecas e museus da Europa, ele volta às ladeiras de Olinda, às paredes do Recife, ouve o rufar dos tambores e o som das vozes de sua gente. ${ }^{37}$ Vazias, as cidades européias, as cidades que habitam o corpo de Anneliese Roos, são de alguma forma preenchidas pela memória de

\footnotetext{
${ }^{34}$ CALVINO, 1990, p. 28.

35 CALVINO, 1990, p. 28.

${ }^{36}$ LINS, 1973, p. 64.

${ }^{37}$ LINS, 1973, p. 76-77.
} 
Abel. É nesse momento que, ainda sem saber, ele começa a construir um outro percurso, em direção aos homens, em direção a Cecília. ${ }^{38}$

Viajante moderno, Abel não poderia deixar de esbarrar em si mesmo ao deslocar-se pela Europa. Mas um tropeção não é um encontro, talvez apenas um sinal, um convite - novo ponto de partida. Encontrar-se, aqui, possui tantos sentidos quanto os tem a Cidade. Vai desde uma espécie de auto-conhecimento, a compreensão das próprias possibilidades e deficiências diante do mundo que o cerca, até a conquista de um espaço seu no universo, aquele lugar no cosmos que lhe garante a imortalidade. E tudo isso, envolvido pela necessidade de realização amorosa, sexual, literária, política... São buscas que se vão entrecruzando, se sobrepondo. Abel não encontra a Cidade na Europa e tampouco se encontra quando finalmente a tem diante de si.

Ao contrário de Anneliese Roos, que é aquilo que representa, a Cidade é símbolo do encontro, mas não o encontro em si. Ao se descortinar, já no final do livro, ela mostra sua face oculta, pérfida:

Contemplo a Cidade, radiosa e insulada, sobre o canavial, contemplo as águas imóveis, os palácios brilhantes como quartzo, as colunas muito altas e, de súbito, como se tivesse nas mãos um pássaro de plumagem sedosa e multicor, e, soprando-a, descobrisse no pássaro um animal escamoso, minado de piolhos, pústulas e vermes, a Cidade, sem nada perder da pompa visível, revela o seu asco, a sua doença, suas camadas maléficas, até aqui dissimuladas. ${ }^{39}$

Condenado, capturado pelo próprio devaneio, Abel grita seu desespero, "quanto erro em buscar essa Cidade única". ${ }^{40}$ Só lhe resta, então, destruí-la.

${ }^{38}$ Enquanto Roos é feita de cidades vazias, o corpo de Cecília é preenchido por multidões.

39 LINS, 1973, p. 410.

${ }^{40}$ LINS, 1973, p. 412. 
E ele a destrói porque revela seu segredo, porque renega seu fascínio, quebra seu sortilégio. Escapando às suas muralhas, ele e

${ }^{41}$ atravessam o tapete da sala de estar - artefato humano, símbolo da tessitura romanesca - e se integram ao Paraíso. Em suma, transpõem aquele limiar do qual falava Abel e "ascendem, mediante novas relações, ao nível da ficção". ${ }^{42}$ Destruir uma cidade, segundo Mircea Eliade, equivale a uma regressão ao Caos. ${ }^{43}$ E só a partir do amorfo, do virtual é possível uma nova Criação, o recomeço. Fechase, assim, o círculo. A serpente - uróboro - morde sua própria cauda, evocando o "perpétuo retorno, o círculo indefinido dos renascimentos, a repetição contínua, que trai a predominância de um fundamental impulso de morte". ${ }^{44}$ Isso porque "a vida não pode ser reparada, mas somente recriada mediante um retorno às fontes". ${ }^{45}$

Cada uma das mulheres por quem Abel se apaixona encerra em si o processo inteiro da sua busca, ao mesmo tempo em que é apenas uma parte dele. Ao ser abandonado por Roos, Abel já enxerga nela alguns dos aspectos da Cidade, que só se revelará mais tarde. O movimento de descoberta é muito semelhante nas duas ocasiões. No final do livro, Abel compara a Cidade a uma pequena ave cuja penugem, quando soprada, denuncia sua podridão. Com Roos, é o suave toque na superfície da água que delata o feio e o sujo:

toco a pele fluida, de leve, docemente, o gesto de quem tentasse afagar, sem enrugá-la, a superfície da água num recipiente, mas a água revolvese, a carne revolve-se, sucedem-se fontes - secas, limosas -, ruas esburacadas, pontes com parapeitos quebrados, casas desoladas margeando um lance de estrada de ferro, postes emaranhados de fios

${ }^{41}$ Último dos amores de Abel, é feita de carne e palavras, uma espécie de síntese das duas anteriores.

${ }^{42}$ LINS, 1973, p. 179.

${ }^{43}$ ELIADE, 1995, p. 47.

${ }^{44}$ CHEVALIER e GHEERBRANT, 1991, p. 923.

${ }^{45}$ ELIADE, 1986, p. 33. 
negros, fachadas de fábricas em ruínas, cheias de vidros poentos e partidos, lixo amontoado em terrenos baldios, canais infectos, jardins abandonados. ${ }^{46}$

Ainda assim, Abel prossegue. Obedece, desconhecendo, às ordens que o Unicórnio, em sonho, dava a Publius Ubonius, ${ }^{47}$ mais de dois mil anos antes: "caminhar sem trégua, não por exemplo em direção ao Norte, mas em espiral, sobre um mapa jamais visto, demarcado pelas cinco palavras simétricas”. ${ }^{48}$ É na Itália, na Biblioteca Marciana, que Abel encontra, por acaso, em meio a trezentos mil outros manuscritos, a versão grega de um longo poema místico dedicado ao Unicórnio. "Seu fundo é a espiral. Um dos temas, a busca do Nome". ${ }^{49}$ O texto é o mesmo cuja organização o "autor" diz imitar "ponto por ponto". ${ }^{50}$ Escrito por um contemporâneo de Ubonius, o poema teria ficado inconcluso, mas estão lá o quadrado mágico e a espiral, as letras e seus significados místicos.

Eis, aí, a criatura diante do plano da criação.

${ }^{46}$ LINS, 1973, p. 188.

${ }^{47}$ Em mais de uma linha narrativa, Osman Lins explica o plano do romance. Numa delas, o modelo da espiral e do quadrado é apresentado a partir da história de um senhor, Publius Ubonius, e seu escravo, Loreius.

${ }^{48}$ LINS, 1973, p. 94.

${ }^{49}$ LINS, 1973, p. 220.

${ }^{50}$ LINS, 1973, p. 96. 


\section{Referências Bibliográficas}

Bíblia sagrada. Petrópolis: Vozes, 1982.

BRUYNE, Edgar de. Estudios de estética medieval, v. 2. Madrid: Gredos, 1958.

CALVINO, Italo. As cidades invisíveis. São Paulo: Companhia das Letras, 1990.

CERTEAU, Michel de. A invenção do cotidiano. Petrópolis: Vozes, 1994.

CHEVALIER, Jean e GHEERBRANT, Alain. Dicionário dos símbolos. Rio de Janeiro: José Olympio, 1991.

COTTERELL, Arthur. Diccionario de mitología universal. Barcelona: Ariel, 1988.

ELIADE, Mircea. Mito e realidade. São Paulo: Perspectiva, 1986.

ELIADE, Mircea. Mito do eterno retorno. São Paulo: Mercuryo, 1992.

ELIADE, Mircea, O sagrado e o profano. São Paulo: Martins Fontes, 1995.

HAUSER, Arnold. História social da literatura e da arte, 2 volumes. São Paulo: Mestre Jou, 1982.

KAPPLER, Claude. Monstros, demônios e encantamentos no fim da Idade Média. São Paulo: Martins Fontes, 1994.

LÉVI-STRAUSS, Claude. Tristes tropiques. Paris: Plon, 1988.

LINS, Osman. Avalovara. São Paulo: Melhoramentos, 1973.

MASSI, Fernanda Peixoto. "O nativo e o narrativo". In: Novos Estudos Cebrap, n 33. São Paulo, 1992, p. 187-198.

POLO, Marco. O livro das maravilhas. Porto Alegre: L\&PM, 1994.

STITES, Raymond S. The arts and man. New York: Whittlesey House, 1940. 


\section{Resumo}

Avalovara, de Osman Lins, fala do homem e de seus enfrentamentos, da criação e da opressão, da eternidade e da História. Percorre diferentes mitos e manifestações artísticas de todos os tempos para relatar a experiência humana. Aqui, se empreende uma leitura possível de parte deste percurso: aquele realizado pelo protagonista do romance, uma personagem em busca de uma cidade, um autor atrás de um texto.

\section{Abstract}

Osman Lins' Avalovara says about man and his confrontation, creation and oppression, eternity and History. It goes through different myths and artistic manifestation of all of times to report the human experience. In this article, I undertake a possible reading of part of this route: the one accomplished by the novel's protagonist, Abel, a character in search of a city, an author after a text. 